\title{
Size-resolved particulate matter composition in Beijing during pollution and dust events
}

\author{
Ann M. Dillner, ${ }^{1}$ James J. Schauer, ${ }^{2,3}$ Yuanhang Zhang, ${ }^{3}$ Limin Zeng, ${ }^{3}$ and Glen R. Cass ${ }^{4,5}$ \\ Received 22 June 2005; revised 12 October 2005; accepted 1 December 2005; published 7 March 2006.
}

[1] Each spring, Beijing, China, experiences dust storms which cause high particulate matter concentrations. Beijing also has many anthropogenic sources of particulate matter including the large Capitol Steel Company. On the basis of measured size segregated, speciated particulate matter concentrations, and calculated back trajectories, three types of pollution events occurred in Beijing from 22 March to 1 April 2001: dust storms, urban pollution events, and an industrial pollution event. For each event type, the source of each measured element is determined to be soil or anthropogenic and profiles are created that characterize the particulate matter composition. Dust storms are associated with winds traveling from desert regions and high total suspended particle (TSP) and PM2.5 concentrations. Sixty-two percent of TSP is due to elements with oxides and $98 \%$ of that is from soil. Urban pollution events have smaller particulate concentrations but $49 \%$ of the TSP is from soil, indicating that dust is a major component of the particulate matter even when there is not an active dust storm. The industrial pollution event is characterized by winds from the southwest, the location of the Capitol Steel Company, and high particulate concentrations. PM2.5 mass and acidic ion concentrations are highest during the industrial pollution event as are $\mathrm{Mn}, \mathrm{Zn}, \mathrm{As}, \mathrm{Rb}, \mathrm{Cd}, \mathrm{Cs}$ and $\mathrm{Pb}$ concentrations. These elements can be used as tracers for industrial pollution from the steel mill complex. The industrial pollution is potentially more detrimental to human health than dust storms due to higher PM2.5 concentrations and higher acidic ion and toxic particulate matter concentrations.

Citation: Dillner, A. M., J. J. Schauer, Y. Zhang, L. Zeng, and G. R. Cass (2006), Size-resolved particulate matter composition in Beijing during pollution and dust events, J. Geophys. Res., 111, D05203, doi:10.1029/2005JD006400.

\section{Introduction}

[2] Beijing, China, is subjected to dust storms in the spring that produce high particulate matter concentrations. The dust storms are caused by high winds traveling over desert regions located to the west and northwest of Beijing. Particulate matter in the desert regions in China is dominated by soil-related species [Zhang et al., 1998]. Anthropogenic sources of particulate matter and its precursors in Beijing include a large steel mill, the Capitol Steel Company, located on the western edge of the city [Sun et al., 2004] as well as dispersed urban sources including industrial, transportation and home heating and cooking sources. Beijing also has local sources of dust from unpaved

\footnotetext{
${ }^{1}$ Crocker Nuclear Laboratory, University of California, Davis, California, USA.

${ }^{2}$ Environmental Chemistry and Technology Program, University of Wisconsin-Madison, Madison, Wisconsin, USA.

${ }^{3}$ College of Environmental Sciences, Peking University, Beijing, China.

${ }^{4}$ School of Earth and Atmospheric Sciences, Georgia Institute of Technology, Atlanta, Georgia, USA.

${ }^{5}$ Deceased 30 July 2001.

Copyright 2006 by the American Geophysical Union. 0148-0227/06/2005JD006400
}

roads and resuspended dust (soil and anthropogenic elements) from paved roads.

[3] In this research, size-resolved, speciated particulate matter samples were collected in Beijing to characterize the high and low particulate matter events during the dust storm season of 2001. Although the large PM concentrations in Beijing during the spring are typically and correctly attributed to dust storms, and in this study, two of the high concentrations events are due to dust storms, one of the high concentration events in this study is ascribed to the Capitol Steel Company and associated industrial activity around the steel mill. Sampling events with lower particulate matter concentrations are attributed to local urban pollution. For each event type, the source (anthropogenic or soil) of each of the measured elements is determined. The classifications and source information are used to create profiles that highlight the size-resolved particulate matter characteristics of dust storm, urban pollution and industrial pollution events between 22 March and 1 April 2001 in Beijing, China.

[4] Although dust storms and the industrial pollution event produce large particulate concentrations which decrease visibility and are a nuisance to the people of Beijing, this research shows that the adverse health effects due to high concentrations from the steel mill and associated 

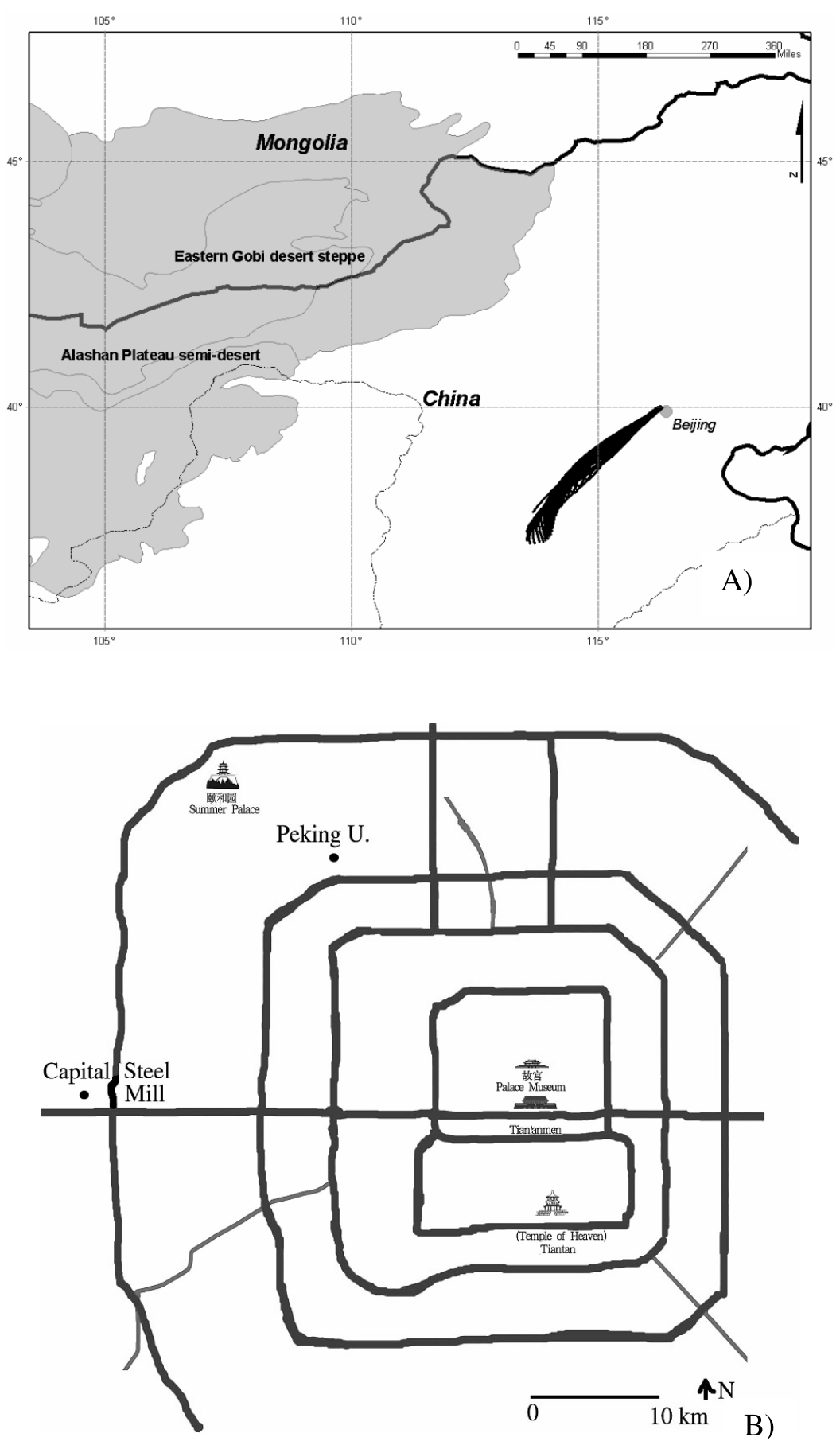

Figure 1. (a) Map of eastern China and Mongolia. Beijing, China, is labeled and desert regions are shaded. The 24-hour back trajectories for each hour during 1 April 2001 are overlaid on the map. (b) Map of Beijing, China, with the sampling site, Peking University, and the major industrial source, Capitol Steel Mill, indicated.

industry may be much higher than due to dust storms because of the much higher concentration of acid and toxic particulate species in the fine fraction.

\section{Methods}

\subsection{Sampling and Chemical Analysis}

[5] A sampling campaign was carried out in Beijing, China, which is located in the northeastern part of China, southeast of the Gobi Desert and Mongolia (Figure 1a). Samples were collected at Peking University, located northwest of central Beijing and northeast of the Capital Steel Company (Figure 1b). The campus is surrounded by traffic, restaurants, and residential apartments, but the campus itself has little traffic. Twenty-four hour size segregated aerosol samples were collected on the roof of a five story academic building. A total suspended particles (TSP) sampler with open-faced filter holders was operated at a nominal flow 
rate of $3 \mathrm{~L} / \mathrm{min}$ (lpm) for each filter. A PM2.5 (particles smaller than $2.5 \mu \mathrm{m}$ in diameter) sampler included filter holders and an Air and Industrial Hygiene Laboratory (AIHL) design cyclone separator and was operated at $24 \mathrm{lpm}$ nominal flow. Two parallel 10-stage micro-orifice uniform deposit impactors (MOUDI, MSP Corp. model 110) [Marple et al., 1991] were operated at a nominal flow rate of $30 \mathrm{lpm}$ and collected particles in six aerodynamic particle size bins: $0.056-0.1,0.1-0.18$, $0.18-0.32,0.32-0.56,0.56-1.0$, and $1.0-1.8 \mu \mathrm{m}$. Each MOUDI had an AIHL design cyclone separator upstream of the inlet to remove particles larger than $1.8 \mu \mathrm{m}$. The flow rate for each sampler was measured before and after each sampling event. Sampled filters and substrates were frozen until physical and chemical analysis was performed.

[6] Gravimetric mass was determined by weighing each Teflon filter (Gelman Teflo, $47 \mathrm{~mm}$ ) and aluminum substrate (MSP Corp., $47 \mathrm{~mm}$ ) a minimum of three times before and after sampling using a Mettler Toledo Model MT5 electronic mass balance at a constant temperature $(20.0 \pm$ $\left.0.4^{\circ} \mathrm{C}\right)$ and relative humidity $(38.5 \pm 4.6 \% \mathrm{RH})$. One set of Teflon filters (Gelman Teflo, $47 \mathrm{~mm}$ ) were prewashed to remove metal contamination [Lough et al., 2005].

[7] Elemental carbon (EC) and organic carbon (OC) concentrations were obtained using thermal methods for quartz filters (Pallflex, $47 \mathrm{~mm}$ ) and foil substrates [Schauer et al., 2003]. Quartz fiber filters and aluminum foils were baked at $550^{\circ} \mathrm{C}$ prior to sampling to eliminate $\mathrm{OC}$ contamination and were stored in annealed, foil lined Petri dishes. Organic compound (OC) concentrations were calculated from the organic carbon by multiplying by a factor of 1.4 to account for atomic species associated with the organic carbon.

[8] The prewashed Teflon filters were cut in half and one half was used to obtain sulfate, nitrate and chloride concentrations using ion chromatography [Mulik et al., 1976] and ammonium by colorimetry [Bolleter et al., 1961].

[9] Element concentrations were obtained by inductively coupled plasma/mass spectrometry (ICP-MS) (VP PlasmaQuad Excell, TJA Solution) for TSP, PM2.5, and the MOUDI stages using the other half of the precleaned Teflon filter [Lough et al., 2005]. Prior to analysis, filters were digested in a microwave assisted acid bath. Fourteen minor elements were quantified using standard hot plasma ICPMS (1350 watt RF) and include Titanium (Ti), Vanadium (V), Chromium (Cr), Manganese (Mn), Copper (Cu), Zinc (Zn), Arsenic (As), Rubidium (Rb), Cadmium (Cd), Antimony ( $\mathrm{Sb})$, Cesium (Cs), Barium (Ba), Cerium (Ce), and Lead $(\mathrm{Pb})$. In addition, three major elements, Sodium $(\mathrm{Na})$, Magnesium (Mg) and Iron (Fe) were quantified in the cool plasma/shielded torch mode of the ICP-MS. Only elements with concentrations larger than the measurement uncertainty were considered quantified. The digestion and ICP-MS analysis method has been validated previously [Schauer et al., 2004].

[10] Elements concentrations for TSP and PM2.5 were also obtained by X-ray fluorescence (XRF) [Watson et al., 1996]. XRF analysis provided concentrations of aluminum $(\mathrm{Al})$, silicon $(\mathrm{Si})$, phosphorus $(\mathrm{P})$, sulfur $(\mathrm{S})$, chlorine $(\mathrm{Cl})$, potassium $(\mathrm{K})$, calcium $(\mathrm{Ca}), \mathrm{Ti}, \mathrm{Mn}, \mathrm{Fe}$, nickel $(\mathrm{Ni}), \mathrm{Cu}$, $\mathrm{Zn}, \mathrm{Rb}$, and $\mathrm{Pb}$. As with ICP-MS, only elements with concentrations above the measurement uncertainty were considered in this analysis.

[11] One set of blank filters and substrates was used to blank correct the measured species mass. Uncertainties in calculated species concentrations were obtained using a propagation of errors technique that included uncertainties in the mass of the species on the sampled and blank filters.

\subsection{XRF and ICP-MS Comparison}

[12] Concentrations of seven elements, Ti, Mn, Fe, Cu, $\mathrm{Zn}, \mathrm{Rb}$ and $\mathrm{Pb}$, were obtained from both XRF and ICP-MS for each sampling event producing 42 elemental comparisons for PM2.5 and TSP. 78\% of PM2.5 comparisons and $70 \%$ of TSP comparisons were not significantly different from each other (95\% confidence). Figure S1 and Text S1 in the auxiliary material ${ }^{1}$ show graphs and discuss in detail the XRF/ICP-MS comparisons. The comparisons which were significantly different were typically on the same sampling days. It is possible that the poor comparisons were due to filter cutting errors. However, comparisons between sulfate and sulfur concentrations did not support that conclusion. For PM2.5, the events with poor comparisons were low concentration events. Differences in the two methods may have been due to incomplete representation of the error at low concentrations, although this was inconclusive since a third low concentration event yields XRF/ICP-MS comparisons that are not significantly different. For TSP, the majority of the samples for which the XRF concentration was significantly higher than the ICP-MS concentration were on 22 and 24 March when the TSP concentration was high due to dust storms. XRF mass results are dependent on particle size and a correction factor to account for the presence of large particles is used [Dzubay and Nelson, 1975]. The correction factor was developed for PM10 samples and may not accurately account for the presence of very large particles during dust storms.

[13] ICP-MS elemental concentrations which include $\mathrm{Mg}$, $\mathrm{Na}, \mathrm{Ti}, \mathrm{V}, \mathrm{Cr}, \mathrm{Mn}, \mathrm{Fe}, \mathrm{Cu}, \mathrm{Zn}, \mathrm{As}, \mathrm{Rb}, \mathrm{Cd}, \mathrm{Sb}, \mathrm{Cs}, \mathrm{Ba}, \mathrm{Ce}$, and $\mathrm{Pb}$, are used for the MOUDI stages, TSP and PM2.5 samples. Al, Si, P, Ca, and $\mathrm{K}$ from XRF are used for PM2.5 and TSP samples. It is assumed that $\mathrm{Al}, \mathrm{Si}, \mathrm{K}, \mathrm{Ca}, \mathrm{Ti}, \mathrm{Mn}$ and $\mathrm{Fe}$ occur in their common oxide forms $\mathrm{Al}_{2} \mathrm{O}_{3}, \mathrm{SiO}_{2}$, $\mathrm{K}_{2} \mathrm{O}, \mathrm{CaO}, \mathrm{TiO}_{2}, \mathrm{Mn}_{2} \mathrm{O}_{7}, \mathrm{Fe}_{2} \mathrm{O}_{3}$ for TSP and PM2.5 samples but this assumption is not made for element concentrations obtained from MOUDI stages because these elements may not occur in this form in small particles. No assumptions are made about the form of the other elemental data presented and their elemental concentrations are given for the element alone. For TSP and PM2.5 samples, the sum of the elements in their common oxide form listed above plus all other elements is called elements with oxides throughout.

\subsection{Data Analysis}

[14] NOAA's HYSPLIT4 trajectory model (www.arl. noaa.gov/hysplit.html) is used to calculate 24-hour backward trajectories assuming isentropic vertical conditions for each hour of aerosol sampling and using meteorological data from NOAA's Gridded Meteorological Data Archive.

\footnotetext{
${ }^{1}$ Auxiliary material is available at ftp://ftp.agu.org/apend/jd/ 2005JD006400
} 

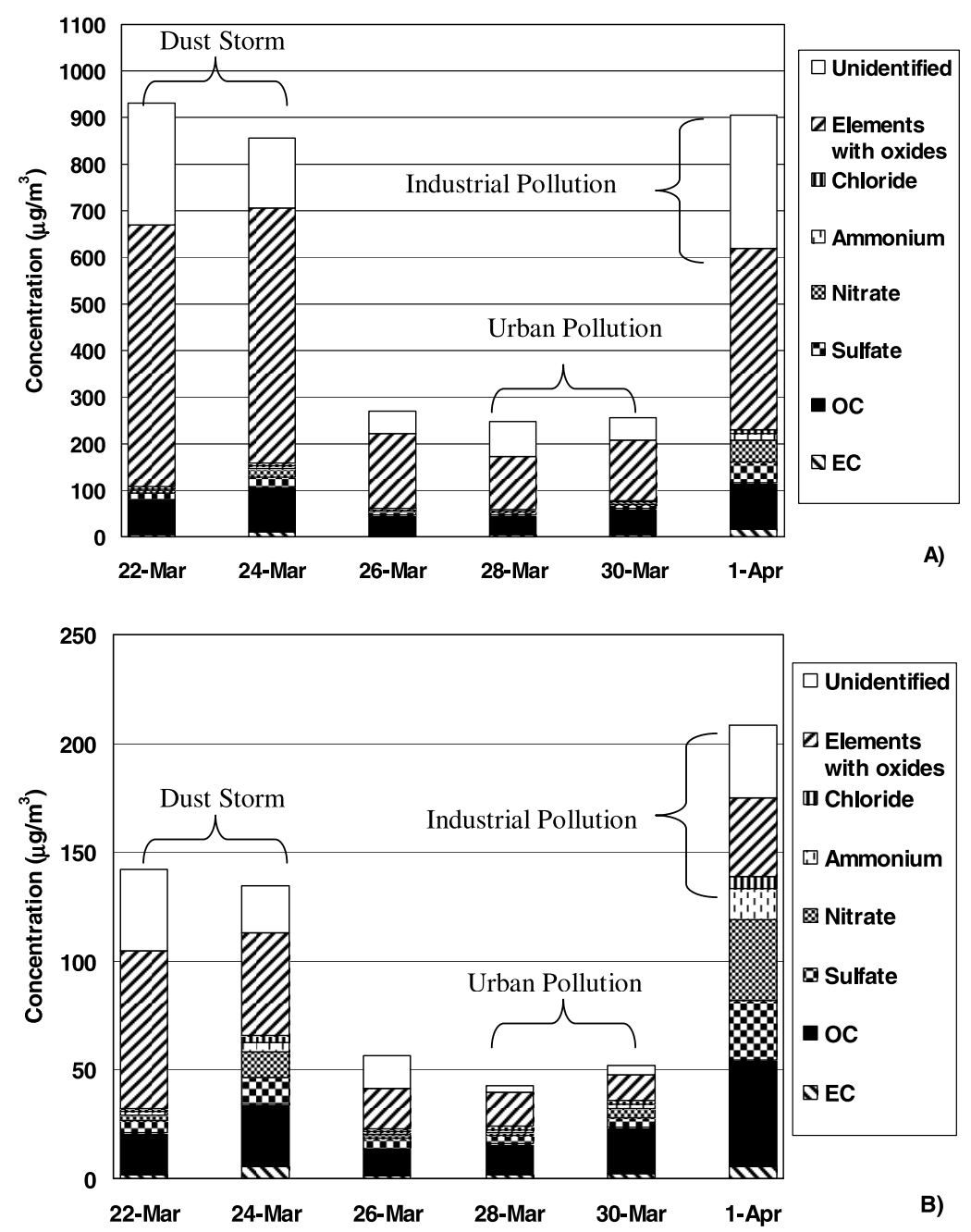

Figure 2. Species concentrations of (a) TSP and (b) PM2.5 in Beijing, China, during spring of 2001. Elements with oxides include the concentration of $\mathrm{Al}_{2} \mathrm{O}_{3}, \mathrm{SiO}_{2}, \mathrm{~K}_{2} \mathrm{O}, \mathrm{CaO}, \mathrm{TiO}_{2}, \mathrm{Mn}_{2} \mathrm{O}_{7}, \mathrm{Fe}_{2} \mathrm{O}_{3}, \mathrm{Na}$, $\mathrm{Mg}, \mathrm{V}, \mathrm{Cr}, \mathrm{Cu}, \mathrm{Zn}, \mathrm{As}, \mathrm{Rb}, \mathrm{Sb}, \mathrm{Cs}, \mathrm{Ce}$, and $\mathrm{Pb}$. Dust storm, urban pollution, and industrial pollution labels indicate sampling events used in profiles discussed in section 3.2.

The trajectories are placed on a map of China that includes the desert regions.

[15] Elemental enrichment factors (EF) using aluminum as the reference element for soil and two bulk soil compositions [Taylor and McLennan, 1985; Lide, 1991], EF = (element/Al $)_{\text {air }} /(\text { element/Al })_{\text {bulk soil }}$, are calculated to aide in assessing which elements measured in the particle matter are from soil. Both of the soil compositions are globally averaged and do not represent Asian dust. No known complete profile of Asian dust is available and the dust from different deserts in Asia have different elemental compositions [Zhang et al., 1997, 1996]. Values of enrichment factors near unity, typically less than 10 , suggest that soil is the primary source of the element. Enrichment factors much higher than 10 suggests that element is mostly due to anthropogenic sources.

[16] A method is implemented that uses cluster analysis to group size distributions of elements that are similar in shape for each sampling event [Dillner et al., 2005]. Measured concentrations are normalized by the sum of concentrations of the MOUDI stages. For profiles which include more than one sampling day, the normalized size distributions are averaged. The squared Euclidian distance is used to calculate the distance between the normalized size distributions of two species and Ward's method [Ward, 1963] is used to cluster the elements based on the calculated distances. The clustering algorithm is applied to each event profile and created two distinct clusters which upon visual inspection have unique size distributions.

\section{Results and Discussion}

\subsection{Categorization and Description of Sampling Events}

[17] The six sampling events are categorized into dust storm days, urban pollution days and an industrial source day using measured speciated TSP and PM2.5 concentrations (Figure $\mathrm{S} 2$ and Tables $\mathrm{S} 1-\mathrm{S} 4$ in the auxiliary material) and calculated back trajectories (Figure 1a for 1 April and Figure S2 in the auxiliary material). The average TSP and PM2.5 concentrations on 22 and 24 March and 1 April are three times higher than on the other sampling days. Back 
trajectories show that on 22 March, strong winds pass over the Gobi desert and Inner Mongolia before reaching Beijing. On 24 March, high winds arrive primarily from the direction of desert regions. 22 and 24 March are therefore determined to be dust storm days. Mass concentrations are also very high on 1 April, but the trajectories (Figure 1a) arrive from the southwest where there are no known deserts [Gong et al., 2004]. PM2.5 concentrations, which are indicative of anthropogenic rather than soil emissions, are higher on 1 April than during any other event as are anthropogenic species including inorganic ions, organic carbon, and some anthropogenic elements but soil elements are lower. The Capitol Steel Company, located southwest of Peking University as shown in Figure $1 b$, is in the path of the wind arriving in Beijing and is the likely source of this high pollution event. Lower TSP and PM2.5 concentrations and somewhat lower wind speeds on 26, 28 and 30 March indicate that these sampling events are influenced primarily by local urban pollution in Beijing. Zhang et al. [2003] determined that there was a severe dust storm in Beijing from 17 to 25 March but no dust storm 26-31 March and 1 April was described as a dusty day (high particulate matter but not from a desert region). Our classifications are in agreement with this earlier work.

[18] TSP daily mass concentrations (Figure 2a) range from $246 \mu \mathrm{g} \mathrm{m}^{-3}$ on $28 \mathrm{March}$ (urban pollution day) to $930 \mu \mathrm{g} \mathrm{m}^{-3}$ on $22 \mathrm{March}$ (dust storm day). Later in the spring, similar TSP concentrations were measured in Beijing ranging from 212 to $894 \mu \mathrm{g} \mathrm{m}^{-3}$ [Cheng et al., 2005]. Elements with oxides are the most abundant class of compounds. The elements with oxide concentrations on dust storm days and the industrial pollution day are three times higher than on urban pollution days.

[19] Eighty-one percent $( \pm 3 \%)$ of the TSP mass is composed of particles larger than PM2.5 $(19 \% \pm 3 \%$ of TSP is PM2.5) during this study, indicating that large particles have a major impact on the air quality in Beijing during the dust storm season.

[20] TSP sulfate, nitrate and ammonium concentrations are largest on the industrial pollution day, which is twice as high as the next highest day, 24 March, a dust storm day. Large secondary inorganic ion concentrations are consistent with major industrial sources which emit large quantities of precursor gases. The sulfate and nitrate concentrations during the dust storm days are significantly higher $(95 \%$ confidence) than during each urban pollution day except for one nitrate comparison. These high sulfate and nitrate concentrations during dust storms may be due to gas phase and/or particle phase sulfur and nitrogen being transported into Beijing with the soil dust or gas phase partitioning of sulfur and nitrogen species to the particle phase due to the large amount of particulate matter in atmosphere. In a model study [Tang et al., 2004], heterogeneous reactions of $\mathrm{SO}_{2}+$ dust and $\mathrm{NO}_{2}+$ dust and $\mathrm{HNO}_{3}+$ dust are used to explain elevated sulfate and nitrate levels on submicrometer particles and a higher percentage of sulfate and nitrate on coarse particles during dust events.

[21] There are several possible causes for the large unidentified mass concentrations observed (Figure 2a). The carbonate, a major component of desert sand in China [Trochkine et al., 2003] is not accounted for in the measurements, nor is water. Also, organic carbon may be more oxidized [Turpin and Lim, 2001] than the factor of 1.4 assumes.

[22] PM2.5 mass (Figure 2b) averages $106 \mu \mathrm{g} \mathrm{m}^{-3}$ during the sampling period in 2001. This is lower than the average PM2.5 concentration of $140 \mathrm{\mu g} \mathrm{m}^{-3}$ measured during April 2000 [Zheng et al., 2005], a major dust storm year. PM2.5 showed similar patterns to TSP except that the highest mass concentration is on the industrial day rather than a dust storm day. The PM2.5 mass concentration on 1 April is 32\% higher than the next highest sampling event. Although elements with oxides are the largest contributor to mass for all events, its relative contribution is lowest on the industrial pollution day. The high mass concentration on 1 April is due to high concentrations of sulfate, nitrate, ammonium, and OC. These species are primarily due to anthropogenic sources and are primarily in the fine fraction.

[23] Sulfate concentrations are highest on 1 April, next highest on 24 March and considerably lower on all other days. Nitrate, OC and EC concentrations follow the same temporal pattern as sulfate.

[24] Similar to TSP, unidentified species concentration are higher on dust storm days than on nondust storm days. On average, $31 \%( \pm 11 \%)$ of PM2.5 mass is unidentified. The cause of the high unidentified mass is likely similar to that discussed for TSP although the OC uncertainty may play a larger role than the soils for PM2.5 since there is a higher percentage of OC in PM2.5 than in TSP.

[25] The speciated mass size distributions of particles less than $1.8 \mu \mathrm{m}$ (Figure S3 in auxiliary material) peak at 1.0$1.8 \mu \mathrm{m}$ for the first five events and one bin lower on 1 April. On 28 and 30 March, both urban pollution days, an additional peak occurs at $0.32-0.56 \mu \mathrm{m}$. The size distributions do not include $\mathrm{Al}, \mathrm{Si}, \mathrm{P}, \mathrm{K}$ and $\mathrm{Ca}$ because these elements were not measured in the size distribution samples.

[26] OC size distributions are always unimodal with broad peaks between 0.32 and $1.0 \mu \mathrm{m}$. Sulfate and ammonium have unimodal size distributions which typically peak at $0.32-0.56 \mu \mathrm{m}$. Nitrate size distributions have peaks at larger size bins during high concentration events $(1-1.8 \mu \mathrm{m}$ on 22 March and $0.56-1.0$ on 24 March and 1 April) than during low concentration events $(0.18-0.32 \mu \mathrm{m})$, suggesting that some of the nitrate particles in the fine fraction was associated with soil during high wind events. There is insufficient ammonium to neutralize the sulfate and nitrate (averaged over 24 hours) for any size bin on any sampling day.

[27] The sum of the elements peak at $0.56-1 \mu \mathrm{m}$ for all events although the peaks are highest during the high wind events, of intermediate height on 26 March and lowest on 28 and 30 March.

[28] The unspeciated mass is likely due in large part to the $\mathrm{Al}, \mathrm{Si}, \mathrm{K}$ and $\mathrm{Ca}$ oxides that were not measured, the associated carbonate and water and uncertainties in $\mathrm{OC}$ correction.

\subsection{Event Profiles}

[29] Measured concentrations obtained in Beijing during the dust storm season are used to obtain profiles of TSP, PM2.5 and size distributions for the three distinct event types, dust storm days, urban pollution days and the industrial pollution day. The profiles highlight the speciated, size-resolved particulate matter composition of each event 
Table 1. TSP Elements Categorized by Source for All Event Types Based on Enrichment Factors

\begin{tabular}{|c|c|c|}
\hline Categorization Method & Soil & Anthropogenic \\
\hline $\begin{array}{l}\text { Enrichment factor from } \\
\quad \text { Taylor and McLennan [1985] }\end{array}$ & $\begin{array}{l}\mathrm{Na}, \mathrm{Mg}, \mathrm{Si}, \mathrm{P}^{\mathrm{a}}, \mathrm{K}, \mathrm{Ca}, \mathrm{Ti}, \\
\text { V, Cr, Mn, Fe, Cu, Rb, Cd, } \\
\text { Cs, Ba, Ce }\end{array}$ & $\mathrm{P}^{\mathrm{a}}, \mathrm{Zn}, \mathrm{As}, \mathrm{Sb}, \mathrm{Pb}$ \\
\hline $\begin{array}{l}\text { Enrichment factor from } \\
\text { Lide [1991] }\end{array}$ & $\begin{array}{l}\mathrm{Na}, \mathrm{Mg}, \mathrm{Si}, \mathrm{P}, \mathrm{K}, \mathrm{Ca}, \mathrm{Ti}, \mathrm{V} \\
\mathrm{Cr}, \mathrm{Mn}, \mathrm{Fe}, \mathrm{Cu}, \mathrm{Rb} \\
\mathrm{Cs}, \mathrm{Ba}, \mathrm{Ce}\end{array}$ & $\mathrm{Zn}, \mathrm{As}, \mathrm{Cd}, \mathrm{Sb}, \mathrm{Pb}$ \\
\hline Final TSP classification & $\begin{array}{l}\mathrm{Na}, \mathrm{Mg}, \mathrm{Al}^{\mathrm{b}}, \mathrm{Si}, \mathrm{P}, \mathrm{K}, \mathrm{Ca}, \\
\mathrm{Ti}, \mathrm{V}, \mathrm{Cr}, \mathrm{Mn}, \mathrm{Fe}, \mathrm{Cu}, \mathrm{Rb}, \\
\mathrm{Cs}, \mathrm{Ba}, \mathrm{Ce}\end{array}$ & $\mathrm{Zn}, \mathrm{As}, \mathrm{Cd}, \mathrm{Sb}, \mathrm{Pb}$ \\
\hline
\end{tabular}

${ }^{\mathrm{a}} \mathrm{P}$ is an anthropogenic element during DS and URB and soil element during IND.

${ }^{\mathrm{b}} \mathrm{Al}$ is the reference soil element used in the enrichment factor method and is assumed to be from soil.

type. The dust storm (DS) profile is the average of the 22 and 24 March concentrations as indicated in Figure 2. Concentrations and size distributions of most species are similar for the two dust storm days. However, for two trace elements $(\mathrm{Cu}$ and $\mathrm{Sb})$ the size distributions and concentrations are considerably different for the two dust storm days. The urban pollution (URB) profile is the average of the second and third urban pollution events, 28 and 30 March (Figure 1). The 26 March event, the first urban pollution event after the dust storm, is excluded from the URB profile based on measured elemental size distributions which show peaks in element size distributions similar to dust storm size distributions. Similar concentrations and size distributions exist for all bulk species for the two urban pollution events. The extent of the similarities and differences between averaged days is discussed below. The industrial pollution (IND) profile is the 1 April data. For profiles which are averages of two days, the percent contribution of each species is calculated for each sampling day and then the percentages are averaged to obtain the percentage of mass due to the species for each profile. Profile averages are calculated using the same sampling events for TSP, PM2.5 and size distributions.

[30] To aide in characterizing each event profile, the major source (anthropogenic or soil) of each element is determined in section 3.3. The sources of the elements are included in the characterization of the three event profiles in section 3.4 .

\subsection{Source of Elements in PM2.5 and TSP: Anthropogenic or Soil}

[31] Enrichment factors for each event type are used to classify elements in TSP (Table 1) using two different reference soil compositions: Taylor and McLennan [1985], hereinafter referred to as Taylor, and Lide [1991], hereinafter referred to as Lide. For both reference soil compositions, $\mathrm{Zn}, \mathrm{As}, \mathrm{Sb}$ and $\mathrm{Pb}$ are classified as anthropogenic elements and all other elements are classified as soil for all event types except for $\mathrm{P}, \mathrm{Cu}$, and $\mathrm{Cd}$. In the PM2.5 analysis discussed below, $\mathrm{Cd}$ is an anthropogenic element for all events and on average $77 \%$ of the Cd in the TSP is from the fine fraction. Therefore $\mathrm{Cd}$ is classified as anthropogenic. Over $96 \%$ of the $\mathrm{P}$ is in particles larger than $2.5 \mu \mathrm{m}$ so it is likely the $\mathrm{P}$ is from soil or fertilizer and is categorized as soil-related. $\mathrm{Cu}$ is classified as soil because it has a low enrichment factor for all events and both soils except one. The final classification of each element is shown in Table 1. Given that $\mathrm{Cd}, \mathrm{P}$ and $\mathrm{Cu}$ together comprise less than $0.07 \%$ of TSP mass, any uncertainty in the classification of these elements does not affect the overall result that over $98 \%$ of the elements with oxide mass in TSP is soil related during all three event types.

Table 2. PM2.5 Elements Categorized by Source for All Event Types Based on Cluster Analysis and Enrichment Factors ${ }^{\mathrm{a}}$

\begin{tabular}{|c|c|c|c|}
\hline Method & Event Type & Soil & Anthropogenic \\
\hline Cluster analysis & $\begin{array}{l}\text { dust storm and } \\
\text { urban pollution }\end{array}$ & $\mathbf{M g}, \mathrm{Ti}, \mathbf{V}, \mathbf{C r}, \mathbf{F e}, \mathrm{Ba}, \mathrm{Ce}$ & $\begin{array}{l}\mathrm{Na}, \mathrm{Mn}, \mathrm{Cu}, \mathrm{Zn}, \mathrm{As}, \mathrm{Rb} \\
\mathrm{Cd}, \mathrm{Sb}, \mathrm{Cs}, \mathrm{Pb}\end{array}$ \\
\hline Cluster analysis & industrial pollution & $\mathrm{Ti}, \mathrm{Ba}, \mathrm{Ce}$ & $\begin{array}{l}\mathrm{Na}, \mathbf{M g}, \mathbf{V}, \mathbf{C r}, \mathrm{Mn}, \mathbf{F e}, \\
\quad \mathrm{Cu}, \mathrm{Zn}, \mathrm{As}, \mathrm{Rb}, \mathrm{Cd}, \mathrm{Sb}, \\
\mathrm{Cs}, \mathrm{Pb}\end{array}$ \\
\hline $\begin{array}{l}\text { Enrichment factor } \\
\text { method from } \\
\text { Taylor and McLennan [1985] }\end{array}$ & all event types & $\begin{array}{l}\mathrm{Na}, \mathrm{Mg}, \mathrm{Al}, \mathrm{Si}, \mathbf{P}^{\mathrm{b}}, \mathrm{K}, \\
\quad \mathrm{Ca}, \mathrm{Ti}, \mathrm{Fe}\end{array}$ & $\begin{array}{l}\mathbf{P}^{\mathrm{b}}, \mathrm{V}, \mathrm{Cr}, \mathrm{Mn}, \mathrm{Cu}, \mathrm{Zn}, \\
\quad \mathrm{As}, \mathrm{Rb}, \mathrm{Cd}, \mathrm{Sb}, \mathrm{Cs}, \mathrm{Ba}, \\
\mathrm{Ce}, \mathrm{Pb}\end{array}$ \\
\hline $\begin{array}{l}\text { Enrichment factor } \\
\text { method from } \\
\text { Lide [1991] }\end{array}$ & all event types & $\begin{array}{l}\mathrm{Na}, \mathrm{Mg}, \mathrm{Al}, \mathrm{Si}, \mathrm{P}, \mathbf{K}^{\mathrm{c}}, \mathrm{Ca}, \\
\mathrm{Ti}, \mathrm{V}, \mathrm{Cr}, \mathrm{Mn}, \mathrm{Fe}, \\
\mathbf{R b}^{\mathrm{c}}, \mathrm{Ba}, \mathrm{Ce}\end{array}$ & $\begin{array}{l}\mathbf{K}^{\mathrm{c}}, \mathrm{Cu}, \mathrm{Zn}, \mathrm{As}, \mathbf{R b}^{\mathrm{c}}, \mathrm{Cd} \\
\quad \mathrm{Sb}, \mathrm{Cs}, \mathrm{Pb}\end{array}$ \\
\hline Final PM2.5 classification & $\begin{array}{l}\text { dust storm and } \\
\text { urban pollution }\end{array}$ & $\begin{array}{l}\mathbf{M g}, \mathrm{Al}^{\mathrm{d}}, \mathrm{Si}, \mathrm{P}, \mathrm{K}, \mathrm{Ca}, \mathrm{Ti}, \mathbf{V}, \\
\quad \mathbf{C r}, \mathbf{F e}, \mathrm{Ba}, \mathrm{Ce}\end{array}$ & $\begin{array}{l}\mathrm{Na}, \mathrm{Mn}, \mathrm{Cu}, \mathrm{Zn}, \mathrm{As}, \mathrm{Rb} \\
\mathrm{Cd}, \mathrm{Sb}, \mathrm{Cs}, \mathrm{Pb}\end{array}$ \\
\hline Final PM2.5 classification & industrial pollution & $\mathrm{Al}^{\mathrm{d}}, \mathrm{Si}, \mathrm{P}, \mathrm{K}, \mathrm{Ca}, \mathrm{Ti}, \mathrm{Ba}, \mathrm{Ce}$ & $\begin{array}{l}\mathrm{Na}, \mathbf{M g}, \mathbf{V}, \mathbf{C r}, \mathrm{Mn}, \mathbf{F e}, \\
\quad \mathrm{Cu}, \mathrm{Zn}, \mathrm{As}, \mathrm{Rb}, \mathrm{Cd}, \mathrm{Sb}, \\
\mathrm{Cs}, \mathrm{Pb}\end{array}$ \\
\hline
\end{tabular}

${ }^{\mathrm{a}}$ Elements in bold type have a different classification depending on the type of event

${ }^{\mathrm{b}} \mathrm{P}$ is soil related during DS and IND and anthropogenic during URB.

${ }^{\mathrm{c}} \mathrm{K}$ and $\mathrm{Rb}$ are soil during DS and URB and anthropogenic during IND.

${ }^{\mathrm{d}} \mathrm{Al}$ is the reference soil element used in the enrichment factor method and is assumed to be from soil. 

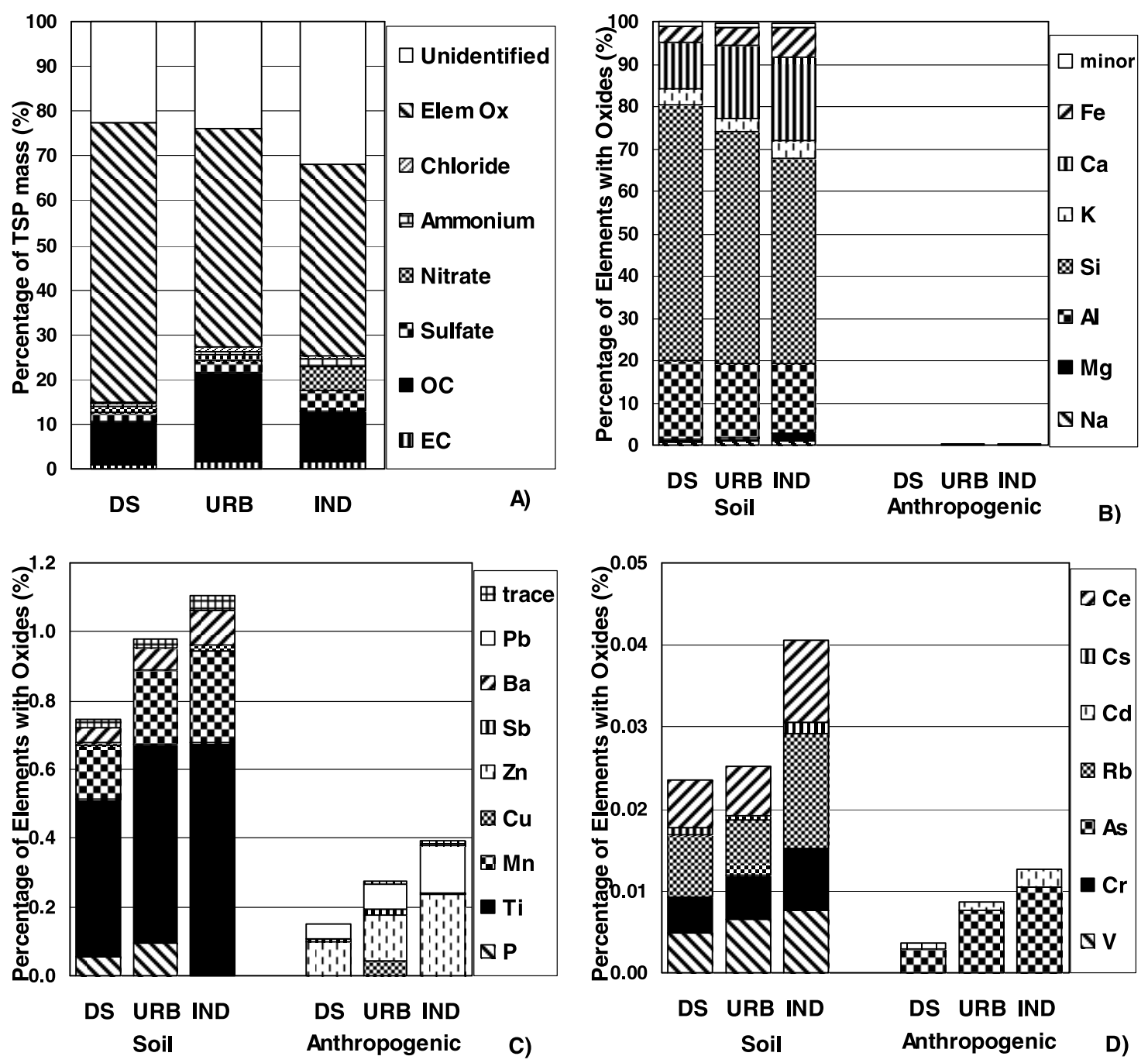

Figure 3. Dust storm (DS), urban pollution (URB), and industrial pollution (IND) profiles for TSP in Beijing for (a) bulk species as a percent of TSP mass, (b) elements with oxides as a percent of TSP elements with oxides, (c) minor elements with oxides as a percent of TSP elements with oxides, and (d) trace elements as a percent of TSP elements with oxides. Elem Ox in the legend is an abbreviation for elements with oxides. Concentrations of $\mathrm{Al}, \mathrm{Si}, \mathrm{K}, \mathrm{Ca}, \mathrm{Ti}, \mathrm{Mn}$, and $\mathrm{Fe}$ are shown in terms of oxide concentrations. Minor elements include $\mathrm{P}, \mathrm{Ti}, \mathrm{Mn} \mathrm{Cu}, \mathrm{Zn}, \mathrm{Sb}, \mathrm{Ba}, \mathrm{Pb}$ and trace elements. Trace elements include $\mathrm{V}, \mathrm{Cr}, \mathrm{As}$, $\mathrm{Rb}, \mathrm{Cd}, \mathrm{Cs}$ and $\mathrm{Ce}$.

[32] Two methods are used to classify PM2.5 elements into soil and anthropogenic. The enrichment factor method can be used for all measured elements but gives less consistent results for PM2.5 than for TSP. For elements with size distribution data, a clustering technique based on elemental size distributions, is utilized to group elements into anthropogenic or soil related elements. The clustering method provides a more direct method for classification than the enrichment factor method because it is based solely on measured data. The results of the cluster method and enrichment factor method are shown in Table 2 along with the final classification of PM2.5 elements.

[33] The cluster technique yields two distinct clusters for each event type. In each case, one cluster contains elements which are typically due to anthropogenic sources such as $\mathrm{Zn}$, As and $\mathrm{Pb}$. The other cluster contains elements typically associated with soil such as $\mathrm{Mg}$ and $\mathrm{Ti}$. The elements clustered in the same two groups for DS and URB profiles but in different groups for IND. Elements which change clusters are in bold in the table. Further description of the size distributions and clusters is at the end of section 3.4.

[34] $\mathrm{Si}, \mathrm{P}, \mathrm{K}$, and $\mathrm{Ca}$, elements without size distribution data, are classified by the enrichment factor method as soil related based on both soil compositions except for $\mathrm{P}$ during $\mathrm{URB}$ event and $\mathrm{K}$ in IND. The enrichment factors for $\mathrm{P}$ are orders of magnitude below 1 (except during the URB using Taylor) indicating that Asian soil has much less $\mathrm{P}$ in it than in the published soil compositions, making the enrichment factor method uncertain. P is assumed to be soil related. Although the enrichment factor for $\mathrm{K}$ is slightly above ten by Lide for IND, $\mathrm{K}$ is classified as soil.

[35] $\mathrm{V}, \mathrm{Cr}, \mathrm{Mn}, \mathrm{Rb}, \mathrm{Ba}$, and $\mathrm{Ce}$ are classified differently by the two soil compositions indicating that at least one of 

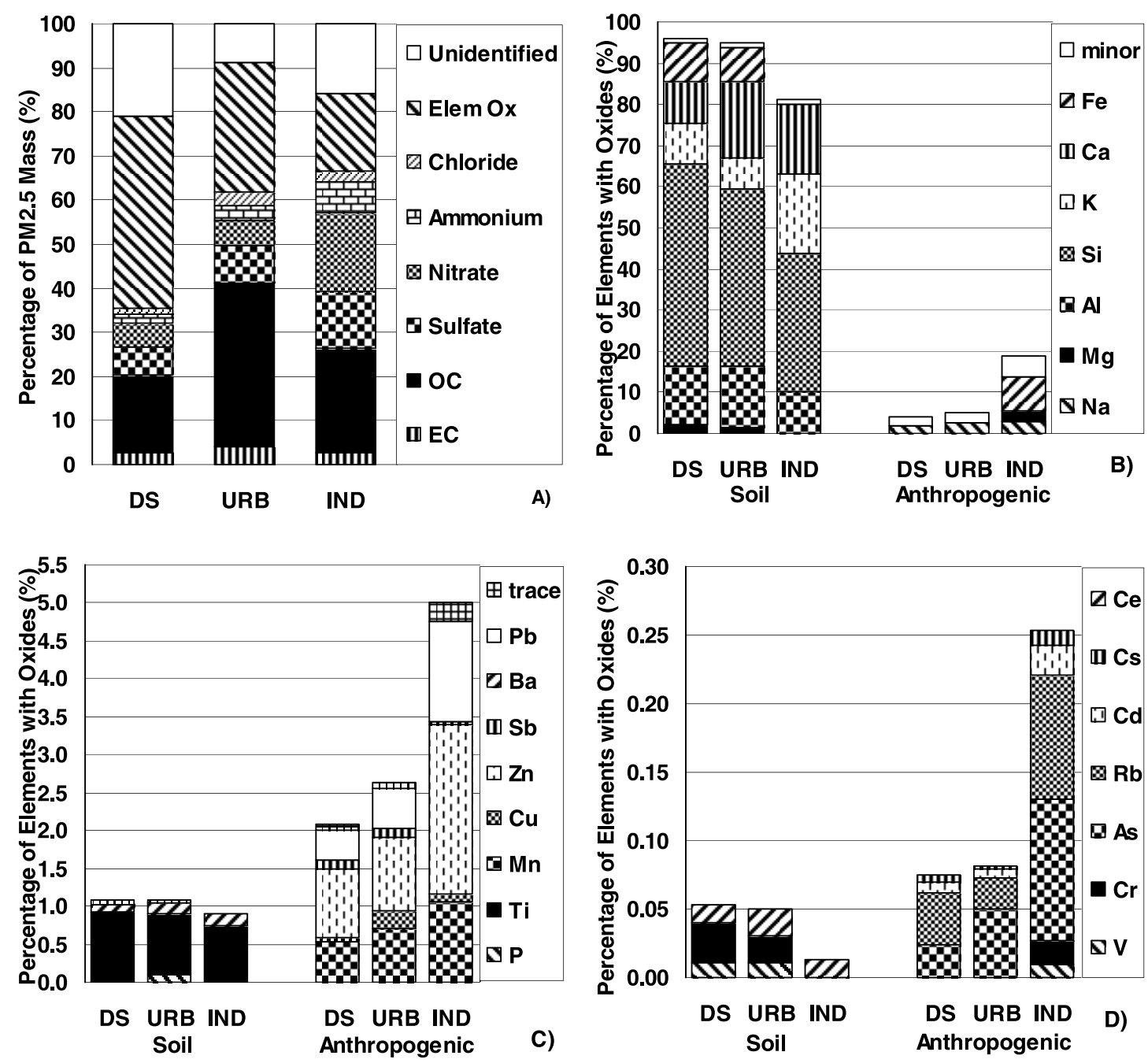

Figure 4. Dust storm (DS), urban pollution (URB), and industrial pollution (IND) profiles for PM2.5 in Beijing for (a) bulk species as a percent of PM2.5 mass, (b) elements with oxides as a percent of PM2.5 elements with oxides, (c) minor elements with oxides as a percent of PM2.5 elements with oxides, and (d) trace elements as a percent of PM2.5 elements with oxides. Elem Ox in the legend is an abbreviation for elements with oxides. Concentrations of $\mathrm{Al}, \mathrm{Si}, \mathrm{K}, \mathrm{Ca}, \mathrm{Ti}, \mathrm{Mn}$, and $\mathrm{Fe}$ are shown in terms of oxide concentrations. Minor elements include $\mathrm{P}, \mathrm{Ti}, \mathrm{Mn} \mathrm{Cu}, \mathrm{Zn}, \mathrm{Sb}, \mathrm{Ba}, \mathrm{Pb}$ and trace elements. Trace elements include V, Cr, As, Rb, Cd, Cs and Ce.

the soil compositions does not correctly represent Asian soil in the fine fraction. In all cases where the enrichment factors give different results, the cluster analysis classification along with additional information is used to determine the final classification. $\mathrm{V}$ and $\mathrm{Cr}$ are typically considered soil related in Asia [Zhang et al., 2003] and are classified as such by Lide and by the cluster method for DS and URB and so are classified as soil for those events. $\mathrm{V}$ and $\mathrm{Cr}$ are classified as anthropogenic during the IND, a high anthropogenic event, by the cluster method and the Taylor enrichment factors and so are categorized as anthropogenic during IND. Mn is classified as anthropogenic by the cluster analysis and one of the two soil compositions so it is considered anthropogenic. $\mathrm{Ba}$ and $\mathrm{Ce}$ are classified as soil by the cluster analysis and one of the two soil compositions and follow the pattern of having the highest percentage of mass during DS and the lowest during IND as do other soil elements and so are included in the soil category. $\mathrm{Rb}$ is classified as anthropogenic by all methods and for the profiles except for DS and URB profiles by Lide. Rb along with elements classified as anthropogenic by all methods, $\mathrm{Zn}, \mathrm{As}, \mathrm{Cd}$ and $\mathrm{Pb}$, have their highest concentration during the IND, so $\mathrm{Rb}$ is classified as anthropogenic.

[36] $\mathrm{Mg}$ and $\mathrm{Fe}$ are classified as anthropogenic by the cluster method and as soil for enrichment factor methods in the IND profile. Na is classified as anthropogenic by the cluster method for all event types but as soil by both enrichment factor analyses. It is likely that the bulk soil composition is not representative of PM2.5 Asian dust especially during the IND event which has high anthropogenic loading. Therefore $\mathrm{Na}, \mathrm{Mg}$ and $\mathrm{Fe}$ during IND and $\mathrm{Na}$ during all events are classified as anthropogenic elements.

\subsection{Dust Storm, Urban Pollution and Industrial Pollution Events}

[37] Figure 3 shows TSP profiles of each event type discussed in section 3.2 evaluated in terms of element 
sources discussed in section 3.3. Figure 3 a shows the relative amount of each bulk species. Figures $3 b, 3 c$, and $3 \mathrm{~d}$ show the relative amounts of all elements with oxides, minor elements with oxides and trace elements, respectively, relative to total elements with oxides and indicate the major source of each element. Major elements are defined as elements which comprise more than $1 \%$ of the TSP elements with oxides, minor elements are elements which comprise between $0.05 \%$ and $1 \%$ and trace elements are less than $0.05 \%$ of the TSP elements with oxides. The values for each species discussed below are reported as a percent of TSP with the relative percent difference given in parentheses. The relative percent difference gives an indication of how similar the two events are to each other.

[38] Figure 3a shows that all profiles are dominated by elements with oxides and that the DS profile has the largest percentage of elements with oxides at $62 \%(6 \%)$, the URB profile has the next at $49 \%(8 \%)$ and IND has the lowest at $43 \%$. OC, which is dominated by anthropogenic sources, is highest during the URB. Inorganic ions, which are largely due to anthropogenic sources, are highest during IND.

[39] For each event type, the profiles of all elements with oxides (Figure 3b) are similar and dominated by $\mathrm{SiO}_{2}$ followed by $\mathrm{Al}_{2} \mathrm{O}_{3}$ and $\mathrm{CaO}$. The percentage due to silicon oxide decreases from DS (60\% (4\%)) to URB (55\% (4\%)) to IND $(48 \%)$ and aluminum oxide has the same although smaller trend. $\mathrm{SiO}_{2}$ and $\mathrm{Al}_{2} \mathrm{O}_{3}$ have very low relative percent differences and all soil elements combined have on average relative differences of $23 \%$ for the DS and $45 \%$ for the URB. Although there is more variability between the two urban pollution days, the low relative percent differences show how strikingly similar the two dust storm events are to each other and the two urban pollution events are to each other in terms of soil elements.

[40] The sum of the minor elements (Figure 3c) and trace elements (Figure $3 \mathrm{~d}$ ) are less than $1.5 \%$ of the elements with oxides composition for TSP. The minor and trace soil related elements have a higher contribution to elements with oxides than anthropogenic elements for all event types.

[41] The PM2.5 profiles for all species (Figure 4a) are dominated by elements with oxides, 47\% (27\%) for DS, $37 \%(43 \%)$ for URB, and $24 \%$ for IND. This is like TSP but with smaller percentages. OC, EC and ions are more prominent in PM2.5 than TSP but follow the same temporal pattern as TSP.

[42] The DS ion, OC and EC profiles are more variable than the URB. For example, the relative percentage difference for sulfate is $77 \%$ for the two dust storm samples but only $3 \%$ for the urban pollution storm events. The high relative percent difference is due to much higher ion and carbon concentrations on 24 March than on 22 March indicating a higher anthropogenic loading on 24 March than on 22 March.

[43] Figure 4b shows the profiles of all elements as a percent of elements with oxides in PM2.5. The relative concentrations of anthropogenic elements are much higher in PM2.5 than TSP. Therefore, for analysis of the impact of anthropogenic sources, PM2.5 concentrations provide much better resolution than TSP concentrations.

[44] Fe (Figure 4b), a major constitute of steel, and V and Cr (Figure 4d) which are often found in steel, are classified as anthropogenic during IND only and are likely emitted from the steel mill. The absolute concentrations and percentage of elements with oxides for $\mathrm{Mn}, \mathrm{Zn}, \mathrm{As}, \mathrm{Rb}, \mathrm{Cd}, \mathrm{Cs}$ and $\mathrm{Pb}$, which are seven of the nine minor and trace elements that are anthropogenic for all events, are higher during the industrial pollution event than during the other events. These elements can be used as tracers of an IND event in Beijing. $\mathrm{Cu}$ and $\mathrm{Sb}$ are two other elements that are anthropogenic for all events but have high concentrations on 24 and 28 March only and are not indicative of any event type. For soil elements, Ti, Ba and $\mathrm{Ce}$, the absolute PM2.5 concentrations are highest during the DS and lowest during the IND event indicating that IND is not as dominated by soil elements as the DS and URB events are.

[45] Soil related elements have a $42 \%$ relative difference in the DS profile and $32 \%$ in the URB profile, similar to TSP soil elements. The anthropogenic elements (excluding $\mathrm{Cu}$ and $\mathrm{Sb}$ ) have relative percent differences for the DS and URB profiles of $78 \%$ and $54 \%$ respectively. The higher differences for the DS are due to higher concentrations on 24 March than 22 March.

[46] Normalized size distributions of $\mathrm{Ti}, \mathrm{Fe}$, and $\mathrm{Ba}$, three representative soil species and $\mathrm{Zn}$, $\mathrm{As}$, and $\mathrm{Rb}$, three representative anthropogenic species, are shown in Figure 5 for the DS, URB and IND profiles. Normalized size distributions of all other elements are in Figures S4, S5, and S6 in the auxiliary material. Size distributions without shading are soil elements and size distributions with black shading are anthropogenic elements. During the DS, the size distributions of soil elements, have a large peak at $0.56-1 \mu \mathrm{m}$. On average $66 \%$ of the mass in the soil element size distributions in the DS profile is in particles larger than $0.56 \mu \mathrm{m}$. For the URB profile (Figure 5b), the highest percentage of mass for the soil elements is in the $1-1.8 \mu \mathrm{m}$ bin producing a coarse tail size distribution, as is typical of local resuspended soil. Recall that size distributions of soil elements on 26 March retained the shape of dust storm size distributions and were therefore excluded from the URB profile. For many soil elements, the absolute mass concentration in the $0.56-1 \mu \mathrm{m}$ bin decreases considerably from DS to URB but the mass concentration in the $1-1.8 \mu \mathrm{m}$ bin remains fairly constant suggesting that the peak in soil elements in the $0.56-1 \mu \mathrm{m}$ bin is due to dust storm and that by 28 March, much of the dust storm soil has been removed from the atmosphere. However, because there are no measured size distributions of the main soil elements, Al, Si and $\mathrm{Ca}$, it cannot be determined from this data if the bulk of the soil is local resuspended soil or dust storm soil that remains in the atmosphere. During the IND, only Ti, Ba and Ce cluster together as soil related elements (Figure 5c). Their size distributions are similar to the soil related DS size distributions but the peak at $0.56-1 \mu \mathrm{m}$ is lower and there is a higher percentage of mass in the $1-1.8 \mu \mathrm{m}$ size bin (particularly for $\mathrm{Ti}$ and $\mathrm{Ce}$ ) suggesting a lower amount of transported soil from the industrial region than during the dust storm.

[47] There is more variability in the shape of size distributions within the anthropogenic cluster than in the soil cluster. Size distributions of elements from high temperature (anthropogenic) sources have peaks below $1 \mu \mathrm{m}$ which vary depending on source type, operating conditions and distance from the sampler [Ondov and Wexler, 1998]. During the DS, anthropogenic elements have a peak at $0.56-1 \mu \mathrm{m}$, just as 

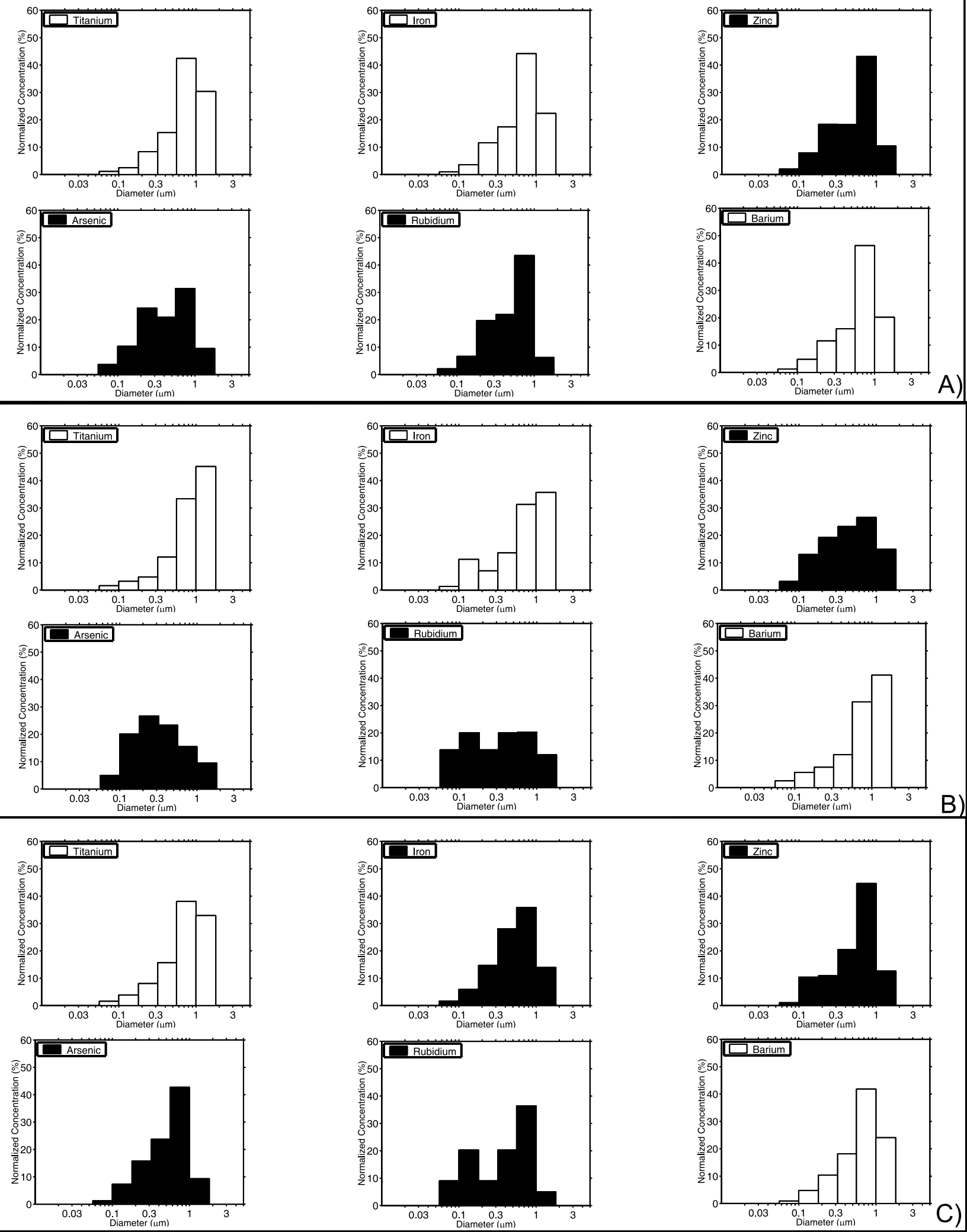

Figure 5. Normalized size distributions of $\mathrm{Ti}, \mathrm{Fe}, \mathrm{Zn}, \mathrm{As}, \mathrm{Rb}$ and $\mathrm{Ba}$ for (a) the dust storm profile, (b) the urban pollution profile, and (c) the industrial pollution profile. Within each profile, the elements with no shading cluster together as soil elements and elements with black shading cluster together as anthropogenic elements. 
the soil elements do, indicating that the DS carries anthropogenic as well as soil elements into the city. However, the anthropogenic species have on average only $45 \%$ of the mass in particles sizes above $0.56 \mu \mathrm{m}$, over $90 \%$ of the mass in the submicrometer size range and often have a secondary peak below $0.56 \mu \mathrm{m}(\mathrm{Na}, \mathrm{As}, \mathrm{Cd}$ and $\mathrm{Pb})$. During the URB, for the anthropogenic elements, the peak at $0.56-1 \mu \mathrm{m}$ decreases or goes away completely, a peak below $0.56 \mu \mathrm{m}$ is often observed and approximately $85 \%$ of the mass is in the submicrometer size range. The anthropogenic element size distributions indicate the importance of high temperature sources to submicrometer particulate levels in Beijing.

[48] During IND, $\mathrm{Mg}, \mathrm{V}, \mathrm{Cr}$, and Fe, cluster with the anthropogenic elements although they are soil related elements in the DS and URB profiles. In addition, peaks below $0.56 \mu \mathrm{m}$ are observed for different elements during the DS than during the IND. These differences in size distributions indicate that different sources are impacting Beijing during the two high particulate matter concentration event types.

[49] Relative percent differences for the DS profile averaged over all elements and size bins is $60 \%$ and for URB it is $44 \%$ with the largest differences in the smallest bins which have the least mass. For the bins between 0.32 and $1.8 \mu \mathrm{m}$, the relative differences are only $38 \%$ and $36 \%$ for DS and URB profile, respectively, showing a high level of consistency between the size distributions of the averaged events.

\section{Conclusions}

[50] During six sampling days in the spring of 2001, Beijing experienced three types of air quality events, dust storms, urban pollution events and an industrial pollution event. Dust storms are characterized by high TSP and PM2.5 concentrations and high winds coming from the desert regions. Dust storm events have high elements with oxides concentrations consisting largely of aluminum and silicon and elevated inorganic ion concentrations compared to urban pollution events. For TSP elements during dust storms, only $\mathrm{Zn}, \mathrm{As}, \mathrm{Cd}, \mathrm{Sb}$ and $\mathrm{Pb}$ are due to anthropogenic sources and over $98 \%$ of the TSP elements with oxides concentrations are due to soil. For PM2.5 elements during dust storms, $\mathrm{Na}, \mathrm{Mg}, \mathrm{Cu}, \mathrm{Rb}$ and $\mathrm{Cs}$ are added to the list of anthropogenic elements, but $96 \%$ of PM2.5 elements with oxides are soil related.

[51] Urban pollution events are characterized by lower TSP and PM2.5 concentrations than dust storms. The urban pollution profile has a high percentage of elements with oxides that are soil for both TSP and PM2.5 indicating the major influence that soil has on the composition of the particulate matter during the dust storm season. OC comprises a much a higher percentage of total PM2.5 mass in the urban pollution profile than in the dust storm profile.

[52] The industrial pollution event has high wind speeds coming from southwest of the sampling site where the large Capitol Steel Company and associated industry are located. The TSP concentrations are similar to dust storm concentrations and the PM2.5 concentrations are higher than dust storm concentrations. The acidic PM2.5 sulfate and nitrate concentrations are two to three times higher during the industrial pollution event than during dust storms and urban pollution events. PM2.5 mass is only about $24 \%$ elements with oxides during the industrial pollution event compared to $47 \%$ during dust storms and $32 \%$ during urban pollution events. The industrial pollution event has higher concentrations and percentages of $\mathrm{Mn}, \mathrm{Zn}$, As, $\mathrm{Rb}, \mathrm{Cd}, \mathrm{Cs}$ and $\mathrm{Pb}$ than either the dust storm or urban pollution events. These elements can be used as tracers for the steel mill industrial complex. For PM2.5, $\mathrm{V}, \mathrm{Cr}$ and $\mathrm{Fe}$ are shown to be of anthropogenic origin although they were soil elements during the other events, suggesting that these elements also are emitted by the steel mill and associated industry. Anthropogenic size distributions have peaks or most of their mass is in particles smaller than $1 \mu \mathrm{m}$ as is expected from high temperature sources. The higher concentration of PM2.5, higher concentration of acidic ions, and higher concentrations of toxic elements such as $\mathrm{Zn}, \mathrm{Cd}$ and $\mathrm{Pb}$ indicate that the high pollution events due to the steel mill and associated industry may have a higher health impact than dust storms. The Chinese government is planning to close the steel mill http://www.chinadaily.com.cn/english/doc/ 2005-02/08/content_415990.htm, http://english.peopledaily. com.cn/200506/10/print20050610_189623.html) which will decrease concentrations of acidic ion and toxic elements in the atmosphere.

[53] Acknowledgments. The authors would like to thank Lynn Salmon for assistance in sampling and for IC and OC/EC analysis, DRI for the XRF analysis, and Mike Arndt for the ICP-MS analysis.

\section{References}

Bolleter, W. T., C. T. Bushman, and P. W. Tidwell (1961), Spectrophotometric determination of ammonium as indophenol, Anal. Chem., 33, $592-594$

Cheng, T., D. Lu, G. Wang, and Y. Xu (2005), Chemical characteristics of Asian dust aerosol from Hunshan Dake Sandland in northern China, Atmos. Environ., 39, 2903-2911.

Dillner, A. M., J. J. Schauer, W. F. Christensen, and G. R. Cass (2005), A quantitative method for clustering size distributions of elements, Atmos. Environ., 39, 1525-1537.

Dzubay, T. G., and R. O. Nelson (1975), Self absorption corrections for $\mathrm{X}$-ray fluorescence analysis of aerosols, in Advances in X-Ray Analyses, edited by W. L. Pickels et al., pp. 619-631, Springer, New York.

Gong, S. L., X. Y. Zhang, T. L. Zhao, and L. A. Barrie (2004), Sensitivity of Asian dust storm to natural and anthropogenic factors, Geophys. Res. Lett., 31, L07210, doi:10.1029/2004GL019502.

Lide, D. R. (1991), Handbook of Chemistry and Physics, CRC Press, Boca Raton, Fla.

Lough, G. C., J. J. Schauer, J. S. Park, M. M. Shafer, J. T. Deminter, and J. P. Weinstein (2005), Emissions of metals associated with motor vehicle roadways, Environ. Sci. Technol., 39(3), 826-836.

Marple, V. A., K. L. Rubow, and S. M. Behm (1991), A microorifice uniform deposit impactor (MOUDI): Description, calibration, and use, Aerosol Sci. Technol., 14(4), 434-446.

Mulik, J., R. Puckett, D. Williams, and E. Sawicki (1976), Ion chromatographic analysis of sulfate and nitrate in ambient aerosols, Anal. Lett., 9, $653-663$

Ondov, J. M., and A. S. Wexler (1998), Where do particulate toxins reside? An improved paradigm for the structure and dynamics of the urban mid-Atlantic aerosol, Environ. Sci. Technol., 32(17), 2547-2555.

Schauer, J. J., et al. (2003), ACE-Asia intercomparison of a thermal-optical method for the determination of particle-phase organic and elemental carbon, Environ. Sci. Technol., 37(5), 993-1001.

Schauer, J. J., G. C. Lough, M. M. Shafer, W. F. Christensen, M. A. Arndt, J. T. DeMinter, and J. S. Park (2004), Characterization and emissions and human exposure to metals emitted from motor vehicles, Health Effects Inst., Boston, Mass.

Sun, Y. L., G. S. Zhuang, W. Ying, L. H. Han, J. H. Guo, D. Mo, W. J. Zhang, Z. F. Wang, and Z. P. Hao (2004), The air-borne particulate pollution in Beijing - concentration, composition, distribution and sources, Atmos. Environ., 38(35), 5991-6004. 
Tang, Y., et al. (2004), Impacts of dust on regional tropospheric chemistry during the ACE-Asia experiment: A model study with observations, J. Geophys. Res., 109, D19S21, doi:10.1029/2003JD003806.

Taylor, S. R., and S. M. McLennan (1985), The Continental Crust: It Composition and Evolution: An Examination of the Geochemical Record Preserved in Sedimentary Rocks, 312 pp., Blackwell Sci., Malden, Mass.

Trochkine, D., Y. Iwasaka, A. Matsuki, M. Yamada, Y.-S. Kim, T. Nagatani, D. Zhang, G.-Y. Shi, and Z. Shen (2003), Mineral aerosol particles collected in Dunhuang, China, and their comparison with chemically modified particles collected over Japan, J. Geophys. Res., 108(D23), 8642, doi:10.1029/2002JD003268.

Turpin, B. J., and H. J. Lim (2001), Species contributions to PM2.5 mass concentrations: Revisiting common assumptions for estimating organic mass, Aerosol Sci. Technol., 35(1), 602-610.

Ward, J. H. (1963), Hierarchical grouping to optimize an objective function, J. Am. Stat. Assoc., 58(301), 236.

Watson, J. G., J. C. Chow, and C. A. Frazier (1996), X-Ray fluorescence analysis of ambient air samples, in Elemental Analysis of Airborne Particles, edited by S. Landsberger and M. Creatchman, pp. 67-96, Gordon and Breach, New York.

Zhang, X. Y., G. Y. Zhang, G. H. Zhu, D. Zhang, Z. S. An, T. Chen, and X. P. Huang (1996), Elemental tracers for Chinese source dust, Sci. China, Ser. D, 39(5), 512-521.
Zhang, X. Y., R. Arimoto, and Z. S. An (1997), Dust emission from Chinese desert sources linked to variations in atmospheric circulation, J. Geophys. Res., 102(D23), 28,041-28,047.

Zhang, X. Y., R. Arimoto, G. H. Zhu, T. Chen, and G. Y. Zhang (1998), Concentration, size-distribution and deposition of mineral aerosol over Chinese desert regions, Tellus, Ser. B, 50(4), 317-330.

Zhang, X. Y., S. L. Gong, Z. X. Shen, F. M. Mei, X. X. Xi, L. C. Liu, Z. J. Zhou, D. Wang, Y. Q. Wang, and Y. Cheng (2003), Characterization of soil dust aerosol in China and its transport and distribution during 2001 ACE-Asia: 1. Network observations, J. Geophys. Res., 108(D9), 4261, doi:10.1029/2002JD002632.

Zheng, M., L. G. Salmon, J. J. Schauer, L. Zeng, C. S. Kiang, Y. Zhang, and G. R. Cass (2005), Seasonal trends in PM2.5 source contributions in Beijing, China, Atmos. Environ., 39(22), 3967-3976.

A. M. Dillner, Crocker Nuclear Laboratory, University of California, Davis, CA 95616, USA. (dillner@ucdavis.edu)

J. J. Schauer, Environmental Chemistry and Technology Program, University of Wisconsin-Madison, Madison, WI 53706, USA.

L. Zeng and Y. Zhang, College of Environmental Sciences, Peking University, Beijing 100871, China. 